\title{
A High Protein Calorie Restriction Diet Alters the Gut Microbiome in Obesity
}

\author{
Tien S. Dong 1,2,3,4® , Kayti Luu 1,2,3,4, Venu Lagishetty 1,2,3,4® , Farzaneh Sedighian 1,2, \\ Shih-Lung Woo ${ }^{5}$, Benjamin W. Dreskin ${ }^{3,4}{ }^{\mathbb{D}}$, William Katzka ${ }^{1,2}$, Candace Chang ${ }^{1,2}$, Yi Zhou ${ }^{1,2}$, \\ Nerea Arias-Jayo 1,2, Julianne Yang ${ }^{1,2}$, Aaron Ahdoot ${ }^{1,2}$, Zhaoping Li ${ }^{2,4,5}$, \\ Joseph R. Pisegna $1,3,4$ and Jonathan P. Jacobs $1,2,3,4, *$ (D) \\ 1 The Vatche and Tamar Manoukian Division of Digestive Diseases, Department of Medicine, \\ David Geffen School of Medicine at UCLA, Los Angeles, CA 90095, USA; \\ tsdong@mednet.ucla.edu (T.S.D.); kaytiluu@gmail.com (K.L.); vlagishetty@mednet.ucla.edu (V.L.); \\ farysedighian@ucla.edu (F.S.); wkatzka@gmail.com (W.K.); candacechang94@gmail.com (C.C.); \\ zhouyisic@gmail.com (Y.Z.); narias@mednet.ucla.edu (N.A.-J.); jcyang1617@g.ucla.edu (J.Y.); \\ aaronahdoot@ucla.edu (A.A.); jpisegna@mednet.ucla.edu (J.R.P.) \\ 2 UCLA Microbiome Center, David Geffen School of Medicine at UCLA, Los Angeles, CA 90095, USA; \\ zli@mednet.ucla.edu \\ 3 Division of Gastroenterology, Hepatology and Parenteral Nutrition, Veterans Administration Greater Los \\ Angeles Healthcare System, Los Angeles, CA 90073, USA; benjamin.dreskin@va.gov \\ 4 Department of Medicine, Veterans Administration Greater Los Angeles Healthcare System, \\ Los Angeles, CA 90073, USA \\ 5 Center for Human Nutrition, David Geffen School of Medicine at UCLA, Los Angeles, CA 90095, USA; \\ shihlungwoo@gmail.com \\ * Correspondence: jjacobs@mednet.ucla.edu; Tel.: +1-310-825-9333
}

Received: 30 September 2020; Accepted: 18 October 2020; Published: 21 October 2020

\begin{abstract}
Background: High protein calorie restriction diets have shown clinical efficacy for obesity, but the mechanisms are not fully known. The intestinal microbiome is a mediator of obesity and preclinical data support an effect of high protein diet (HPD) on the gut microbiome of obesity, but there are few studies in humans. Methods: To address this, we conducted a dietary intervention trial of 80 overweight and obese subjects who were randomized to a calorie-restricted high protein diet (HPD) ( $30 \%$ calorie intake) or calorie-restricted normal protein diet (NPD) (15\%) for 8 weeks. Baseline dietary intake patterns were assessed by the Diet History Questionnaire III. Longitudinal fecal sampling was performed at baseline, week 1 , week 2 , week 4 , week 6 , and week 8 , for a total of 365 samples. Intestinal microbiome composition was assessed by 16S rRNA gene sequencing. Results: At baseline, microbial composition was associated with fiber and protein intake. Subjects on the HPD showed a significant increase in microbial diversity as measured by the Shannon index compared to those on the NPD. The HPD was also associated with significant differences in microbial composition after treatment compared to the NPD. Both diets induced taxonomic shifts compared to baseline, including enrichment of Akkermansia spp. and Bifidobacterium spp. and depletion of Prevotella spp. Conclusion: These findings provide evidence that weight loss diets alter the gut microbiome in obesity and suggest differential effects of HPDs compared to NPDs which may influence the clinical response to HPD.
\end{abstract}

Keywords: high protein diet; calorie restriction; microbiome; obesity; randomized controlled trial

\section{Introduction}

Obesity has rapidly increased in prevalence in recent decades and now affects approximately one third of the population of the United States [1]. This epidemic has resulted in rising rates of 
type II diabetes mellitus, nonalcoholic fatty liver disease, dyslipidemia and arteriosclerosis as well as certain forms of cancer, including colorectal and pancreatic cancer. Dietary intervention and increased physical activity are the cornerstones of non-surgical management of obesity [2]. A wide range of diets have been studied to treat obesity, but a consensus has not been reached on an optimal macronutrient composition. A low-fat, high carbohydrate diet has traditionally been recommended; however this was challenged by alternative diets including those with increased protein and reduced carbohydrate intake. An early study reported that subjects randomized to ad libitum diets with $25 \%$ protein intake had greater weight and fat loss than subjects on a 12\% protein diet over 6 months [3]. Further insight was provided by two large-scale randomized clinical trials-each with approximately 800 subjects-comparing the performance of isocaloric restriction diets with varying concentrations of carbohydrate, protein, and fat $[4,5]$. Subjects on diets with greater protein content had increased weight loss, reduced weight regain in the maintenance phase, and greater decrease in insulin. A metaanalysis of randomized studies comparing high protein and normal protein isocaloric restriction diets showed statistically significant decreases in weight, fat mass, and triglycerides with high protein diets (HPD) compared to normal protein diets (NPD) [6].

The underlying mechanisms of enhanced weight loss with an HPD are incompletely characterized. HPDs have been shown to promote satiety relative to isocaloric diets with more carbohydrates or fat $[7,8]$. This effect has been attributed to induction of satiety hormones including glucagon, glucagon-like peptide-1, and peptide YY 3-36 [8,9]. In clinical studies of ad libitum feeding, HPDs are associated with reduced energy intake relative to normal protein diets $[3,10]$. However, HPDs have also shown efficacy compared to isocaloric diets, indicating that other mechanisms are involved. It has also been proposed that weight loss is secondary to increased thermogenesis and preservation of lean body mass, maintaining resting energy expenditure [6,11,12]. This is supported by a study demonstrating that a high protein diet mitigates the reduction in resting and total energy expenditure that occurs on a calorie restricted diet [13].

There is now considerable evidence that the intestinal microbiome plays an important role in the pathogenesis of obesity. Germ-free mice have lower body fat and resistance to diet-induced obesity that are rapidly reversed upon microbial colonization $[14,15]$. Obese humans and mice have distinct intestinal microbiota from lean controls that induce increased body fat accumulation when transferred into germ-free mice compared to the microbiota of lean donors [16-19]. In addition, mice with microbiota alteration due to genetic defects in host immune pathways develop susceptibility to diet-induced obesity that can be transmitted to other mice by fecal transplantation [20,21]. Moreover, formerly obese mice have persistent changes in their microbiome that confer transmissible susceptibility to diet-induced obesity [22].

Long-term dietary patterns are correlated with microbiome composition and interventional diets can rapidly change microbial composition, raising the possibility that the microbiome is involved in the response to weight loss diets [23-25]. Higher dietary protein content in healthy volunteers has been associated with increased likelihood of a Bacteroides spp-predominant microbiota [24]. In animal models, HPDs have been shown to affect the microbiome of normal weight mice and rats after both short-term and prolonged feeding [26-29]. We recently demonstrated that switching rats with Western diet-induced obesity from a high fat to a high protein diet induces changes in the microbiome including enrichment of Akkermansia muciniphila, which had an inverse correlation with body fat mass [30]. This microbe has previously been reported to be enriched after bariatric surgery and to confer reduced adiposity and hyperglycemia in mice with diet-induced obesity [31-33].

We hypothesize that HPDs modulate the microbiome associated with human obesity, which may contribute to their clinical efficacy. Little data is currently available on the effects of high-protein weight loss diets on microbial composition in obese human populations. A non-randomized study of 19 obese participants placed on an HPD reported reduced Roseburia/Eubacterium rectale and Bifidobacterium spp. based on measurement of nine bacterial groups by fluorescence in situ hybridization [34]. In contrast, a more recent, randomized controlled study of two HPDs for 3 weeks with 12-13 overweight subjects per 
arm did not observe an effect of dietary intervention on the fecal microbiome using sequencing-based methodology [35]. To address this knowledge gap, we performed a randomized clinical study comparing the effect of isocaloric high and normal protein diets on the intestinal microbiome of a cohort of 80 overweight and obese subjects followed longitudinally for 8 weeks.

\section{Materials and Methods}

\subsection{Patient Recruitment}

Patient recruitment occurred at the West Los Angeles VA Medical Center (ClinicalTrials.gov Identifier: NCT01146704). Patients were eligible for recruitment if they were between 20 and 75 years of age, BMI 27 to $40 \mathrm{~kg} / \mathrm{m}^{2}$, non-smoker or stable smoking habits for at least 6 months prior to screening and agreement not to change such habits during the study. Patients were excluded if they had significant weight change of $>3.0 \mathrm{~kg}$ in the month prior to screening, weight loss of $>10 \mathrm{~kg}$ in the 6 months prior to screening, were on a calorie restriction diet ( $<1500 \mathrm{kcal} / \mathrm{day})$ for a period of 4 months or more in the 12 months prior to screening, use of any other investigational drug(s) within 8 weeks prior to screening, abnormal baseline laboratory parameters (serum creatinine $>1.6 \mathrm{mg} / \mathrm{dL}$; alanine aminotransferase, aspartate transaminase, total bilirubin $>2.0$ times the upper limit of normal; triglycerides $>500 \mathrm{mg} / \mathrm{dL}$, total cholesterol $>350 \mathrm{mg} / \mathrm{dL}$, thyroid stimulating hormone outside of normal range), consumption of more than one alcoholic beverage per day, pregnancy or intention to become pregnant. All patients gave verbal and written consent to be part of the trial. The study was conducted in accordance with the Declaration of Helsinki, and the protocol was approved by the Greater Los Angeles VA Institutional Review Board (Project identification code: 2017-121121).

\subsection{Enrollment and Randomization}

Date of birth, sex, race, medical history, current medications, smoking and alcohol history were obtained during the screening visit. Metabolic syndrome was defined using the National Cholesterol Education Program (NCEP) Adult Treatment Panel III (ATP III) definition. Briefly, metabolic syndrome was defined as having any three of the following five criteria: waist circumference $>40$ inches in males or 35 inches in females, fasting glucose $\geq 100 \mathrm{mg} / \mathrm{dL}$ or history of diabetes mellitus on therapy, triglycerides $\geq 150 \mathrm{mg} / \mathrm{dL}$ or on therapy for hypertriglyceridemia, high density lipoprotein (HDL) $<40 \mathrm{mg} / \mathrm{mL}$ in males or $<50 \mathrm{mg} / \mathrm{dL}$ in females or was on therapy to raise their HDL, or blood pressure $>130 \mathrm{mmHg}$ systolic or $>85 \mathrm{mmHg}$ diastolic or was on therapy for hypertension [36]. After enrollment, patients were randomized to one of two diet groups using a random number generator.

\subsection{Dietary Intervention}

Participants were randomized to an HPD (30\% protein, 40\% carbohydrate, 30\% fat by calorie intake) or an NPD (15\% protein, 55\% carbohydrate, 30\% fat) (i.e., control group). The diet was implemented in two phases: an initial macronutrient standardized diet without calorie restriction for 2 weeks then the same macronutrient standardized diet with a deficit of 500 calories from their calculated metabolic rate for 6 weeks. Basal metabolic rate was calculated using the InBody Scanner (Cerritos, CA, USA) body composition analysis, adjusting for routine daily activity by multiplying the basal metabolic rate by 1.2. Subjects received dietary counseling during their baseline visit on their assigned macronutrient standardized diet. After 2 weeks of a macronutrient standardized diet, both groups then received further dietary counseling on how to restrict their intake. Pea-based protein supplements (Nutrasumma, Phoenix, AZ, USA) were provided to the HPD group to achieve the target of $30 \%$ calories from protein in the HPD group. A control supplement containing dextrose that matched the calories of the protein supplement was given to the NPD group (Table 1). All patients, study coordinators, and medical doctors involved were blinded to the patient's assignment. 
Table 1. Meal plan between the study arms and supplement characteristics per serving.

\begin{tabular}{ccc}
\hline & NPD & HPD \\
\hline Meal Plans (\% of Total Calories/Day) Including Supplement \\
Grains/Starch & 20 & 10 \\
Vegetables & 15 & 15 \\
Protein & 15 & 30 \\
Fruit & 20 & 15 \\
Fats and Oils & 30 & 30 \\
Supplement Characteristics per Serving & \\
Calories & 100 & 100 \\
Total Fat & $0 \mathrm{~g}$ & $1 \mathrm{~g}$ \\
Total Carbohydrate & $22 \mathrm{~g}$ & $1 \mathrm{~g}$ \\
Protein & $0 \mathrm{~g}$ & $20 \mathrm{~g}$ \\
Sodium & $160 \mathrm{mg}$ & $290 \mathrm{mg}$ \\
Potassium & $45 \mathrm{mg}$ & $35 \mathrm{mg}$ \\
\hline
\end{tabular}

NPD: Normal Protein Diet; HPD: High Proteing Diet.

\subsection{Nutritional Assessments}

Nutritional assessment was done at baseline using the Diet History Questionnaire III [37], a self-administered, semi-quantitative tool that queries the average frequency of consumption over the prior to one month of a list of food items. It is supported by the National Cancer Institute and was previously validated against other FFQs [38]. The extensive nutrient composition database that supports the questionnaire allows estimation of macronutrient intake. We used the United States Department of Agriculture's (USDA) guideline for fiber and protein intake as the cutoffs for meeting recommended fiber and protein intake at baseline. For fiber, it meant taking in at least $38 \mathrm{~g}$ of fiber per day for males 50 years of age or younger and $25 \mathrm{~g}$ per day for females 50 years of age or younger. If the patients were over 50, the recommended daily fiber was $30 \mathrm{~g}$ and $21 \mathrm{~g}$ for males and females, respectively. For protein, we used the USDA's recommended daily allowance of $0.8 \mathrm{~g}$ of protein per kilogram.

\subsection{Fecal Sampling}

Participants were provided with kits for home sampling at baseline, week 1 , week 2, week 4 ( 2 weeks of calorie restriction), week 6 (4 weeks of calorie restriction), and week 8 (6 weeks of calorie restriction). Stool samples were collected in a Para-Pak stool collection cup prefilled with $95 \%$ ethanol to fix the samples, allowing storage at room temperature for up to 2 weeks [39]. Samples were stored at $-80^{\circ} \mathrm{C}$ until undergoing DNA extraction using the ZymoBIOMICS DNA Microprep Kit (Zymo Research, Irvine, CA, USA) per the manufacturer's protocol. Sequencing of the 253 base pair V4 region of $16 \mathrm{~S}$ ribosomal DNA was performed as previously described using the Illumina NovaSeq 6000 to a depth of 250,000 reads per sample (primer set: 515f/806r) [40]. The sequences were processed with the DADA2 pipeline in $\mathrm{R}$ which assigns taxonomy using the SILVA 132 database [41]. After pre-processing in R, the data were imported into QIIME 2 version 2019.10 for further analysis [42]. Amplicon sequence variants were filtered if not present in at least $15 \%$ of all samples. Sequence depth ranged from 10,302 to 519,991 with a mean of $204,216 \pm 71,888$ per sample.

\subsection{Statistical Analysis}

Baseline clinical characteristics were compared between the two arms using analysis of variance for continuous variables and chi-squared test for categorical variables. All means are presented along with their standard deviations.

Microbiome data was analyzed for alpha diversity, beta diversity, and differential abundance of individual taxa. Because race was significantly associated with microbial outcomes at baseline, all analysis was adjusted for race. A composite category of race and ethnicity was used where we 
identified non-white Hispanics as a separate race category. Alpha diversity was calculated using the Shannon index (a metric of species evenness and richness) with data rarefied to 10,301 sequences. The significance of differences in alpha diversity was calculated by analysis of variance. Beta diversity was assessed using the DEICODE plugin in QIIME 2 which employs a robust Aitchison distance metric. This newer form of beta diversity metric accounts for the sparse compositional nature of microbiome data and has been shown to yield higher discriminatory power when compared to other used metrics such as UniFrac or Bray-Curtis [43]. Statistical significance of differences in beta- diversity was assessed using permutational multivariate analysis of variance (adonis package in R), with models including dietary intervention group, study time point, and subject. Baseline differences in taxa abundances were analyzed using DESeq2 in R (version 4.0.3, Vienna, Austria), which employs an empirical Bayesian approach to shrink dispersion and fit non-rarified count data to a negative binomial model [44]. For longitudinal samples, we used generalized linear mixed effects models implemented in the R package glmmTMB with the subject as a random effect [45]. $p$-values were adjusted for multiple hypothesis testing using the Benjamin-Hochberg procedure and the significance threshold was set at p.adj $<0.05$.

\section{Results}

A total of 131 patients were screened to be recruited in the study (Figure 1). Fifty-one patients were excluded. Three patients were excluded because they did not meet inclusion/exclusion criteria while the remaining 48 patients declined to participate. Eighty patients were enrolled and randomized into the two arms. At the end of the 8 weeks follow up period, there were 29 patients in the NPD arm and 31 patients in the HPD arm. The most common reason for drop out was that the patient no longer wanted to participate in the study due to time constraints.

The patients in the NPD and HPD groups did not differ by any baseline demographic or clinical parameter (Table 2). Because the study only included veterans receiving their medical care at the VA Greater Los Angeles Healthcare System, the majority of the patients ( $>75 \%$ ) were male. The average age was 55.7 years in the NPD group and 55.9 years in the HPD group. The average body mass index was 34.6 in the NPD group and 34.9 in the HPD group. The two groups did not differ by the presence of diabetes mellitus, the presence of metabolic syndrome or race. Baseline macronutrient and fiber intake was also not statistically different between the two groups. At the end of 8 weeks, the HPD lost more weight on average than the NPD group $(3.46 \mathrm{~kg}$ vs. $2.83 \mathrm{~kg})$, though the results were not statistically significant $(p$-value $=0.34)$.

Baseline microbiome profiles did not differ between the two groups by either alpha or beta diversity analysis (data not shown). There were also no significant differences of baseline microbiome diversity or composition in relationship to baseline fiber or protein intake (Figure 2). Baseline fiber and protein intake was classified as either meeting the recommended daily intake according to USDA guidelines or not meeting the recommended daily intake. The baseline abundances of genera with greater than 1\% mean relative abundance are shown in Figure 2E for subjects in the study, stratified by baseline fiber and protein intake. Differential abundance testing identified three genera that significantly differed between those meeting the daily recommended intake of fiber versus those that did not. Akkermansia spp. and Lactobacillus spp. were enriched in patients with higher fiber intake, and Prevotella_7 spp. was depleted in patients with higher fiber intake. Similarly, three genera were found to be differentially abundant between those meeting the daily recommended intake of protein versus those that did not. Prevotella_7 spp. and Blautia spp. were elevated in patients with higher protein intake, and Megamonas spp. was lower in patients with higher protein intake. 


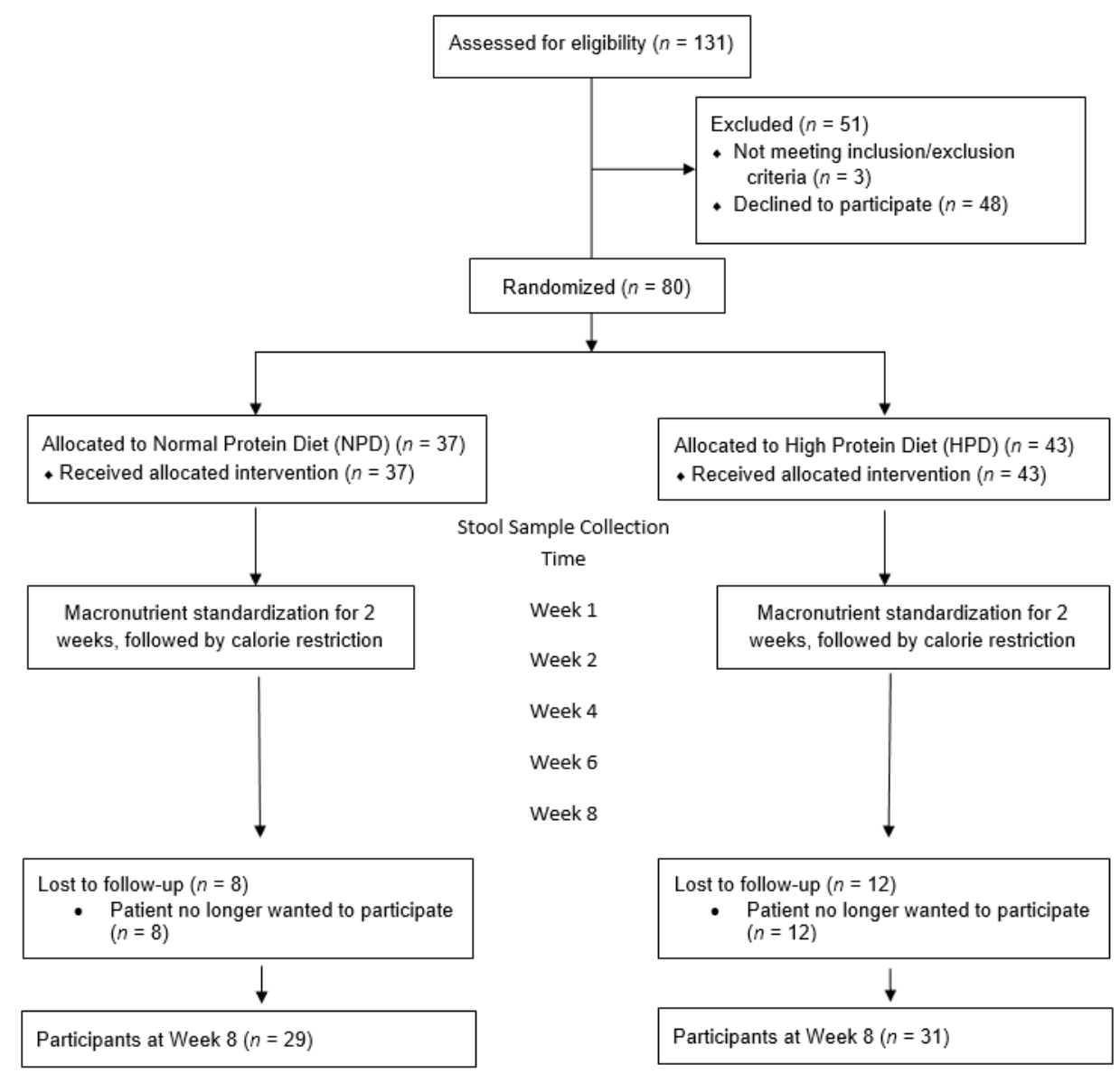

Figure 1. Study flow diagram.

After patients were randomized and placed on either an HPD or NPD diet with calorie restriction, significant changes in microbial diversity and composition were observed (Figure 3). There was an initial decrease in alpha diversity as assessed by the Shannon index when patients transitioned to a standardized macronutrient diet (Figure 3A). This was evident in both the NPD and HPD group. However, at the end of 8 weeks ( 6 weeks of calorie restriction), the alpha diversity of the NPD group remained unchanged compared to baseline while the HPD group significantly increased. At the end of the 8-week trial, patients on the HPD had a significantly higher Shannon index as compared to those on the NPD ( $p$-value $<0.05)$. This increase in diversity was apparent in the white and African-American subjects in the HPD group but not the Hispanic subjects (Figure 3B). The taxonomic summary of the two groups across the various time points is shown in Figure 3C. Beta diversity analysis demonstrated that there was a statistically significant difference in microbial composition between the HPD and NPD groups when considering all study time points together and adjusting for subject effects $(p$.adj value $=0.001)$ (Figure 3D). There was no beta diversity difference by study visit ( .adj value $=0.88$ ).

Differential abundance testing demonstrated that there were genera that changed over the course of the study irrespective of diet, and genera that changed specifically due to higher protein intake (Figure 4). Twenty-three genera were either enriched or depleted at 8-weeks as compared to baseline, independent of protein intake. The majority of the genera belonged to the phylum Firmicutes. The three genera with the highest relative abundance were Akkermansia, Bifidobacterium, and Prevotella_9. Akkermansia spp. and Bifidobacterium spp. were elevated at 8-weeks as compared to baseline while Prevotella_9 was decreased at 8-weeks as compared to baseline. The HPD intervention resulted in differential abundance of six genera as compared to the NPD group when considering all study time points together. The majority of the genera belonged to the phylum Firmicutes. The three genera with 
the highest relative abundances were Prevotella_2, Faecalibaculum, Lachnospiraceae_UCG-004. All three genera were underrepresented in patients on the HPD as compared to the NPD group. The genus that was most strongly enriched in the HPD group was Gemella.
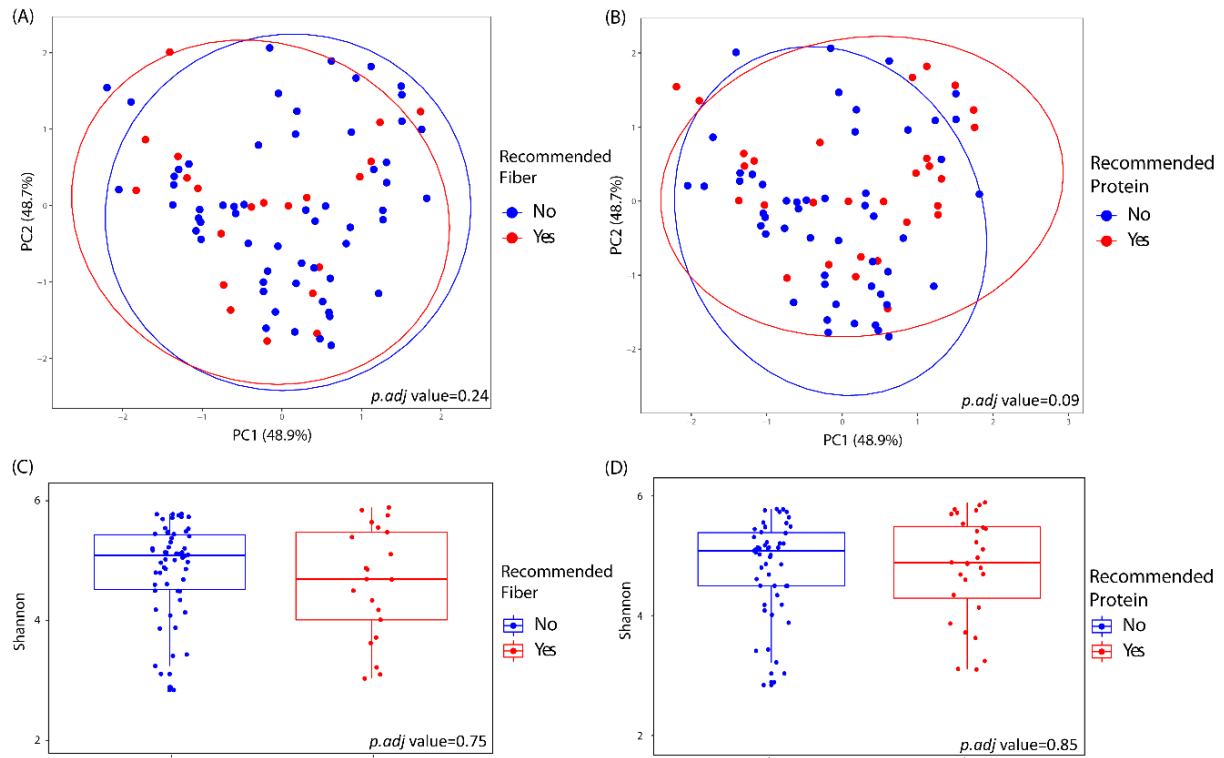

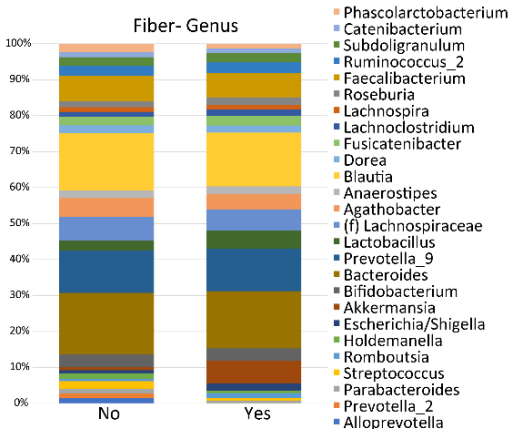

(G) Recommended Fiber: Yes vs No

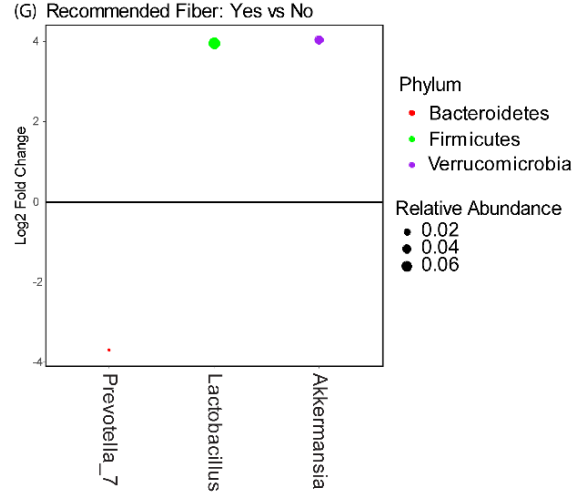

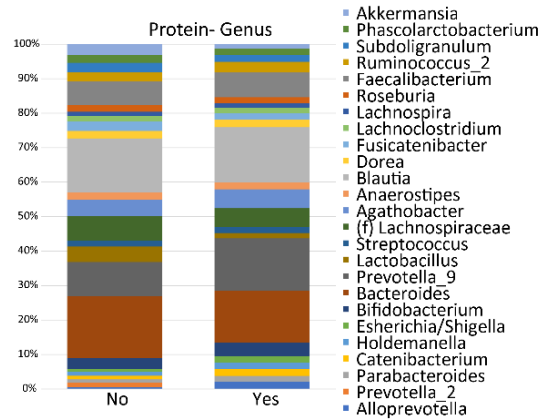

(H) Recommended Daily Protein: Yes vs No

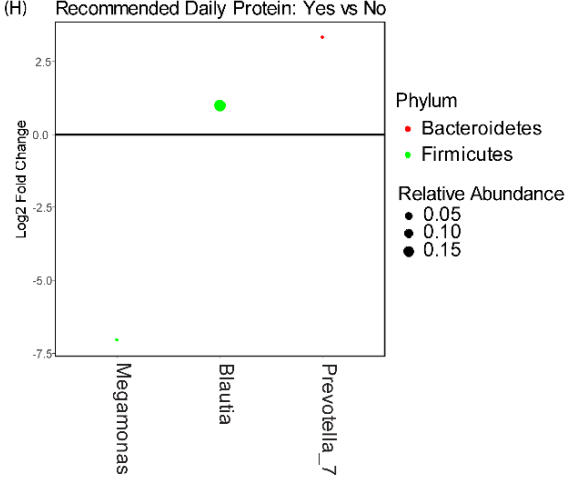

Figure 2. Baseline microbiome differences by protein and fiber intake. (A,B) Principal coordinates analysis plots of microbial community makeup by (A) recommended fiber intake and (B) recommended protein intake. (C,D) Shannon index of microbial diversity by (C) recommended fiber intake and (D) recommended protein intake. (E,F) Taxonomic summary plots by (E) recommended fiber intake and $(\mathrm{F})$ recommended protein intake. Only genera with $\geq 1 \%$ relative abundance are shown. $(\mathbf{G}, \mathbf{H})$ Differentially abundant genera by DESeq2 analysis between subjects at baseline stratified by (G) recommended fiber intake or $(\mathbf{H})$ recommended protein intake. Genera that are above 0 represent genera that have a higher abundance in patients who are taking in the recommended amount of fiber or protein as compared to those that are not. Dots are colored by phylum and sized by mean relative abundance across all samples. 
Table 2. Baseline cohort characteristics.

\begin{tabular}{|c|c|c|c|}
\hline & NPD $(n=37)$ & HPD $(n=43)$ & $p$-Value \\
\hline Gender (\% Males) & 78.4 & 76.7 & 0.86 \\
\hline Age (years) (SD) & $55.7(11.4)$ & $55.9(10.1)$ & 0.91 \\
\hline BMI & $34.6(5.1)$ & $34.9(4.5)$ & 0.8 \\
\hline Weight (kg) (SD) & $104.3(18.1)$ & $104.7(18.4)$ & 0.93 \\
\hline Presence of DM (\%) & 27.0 & 32.6 & 0.59 \\
\hline Presence of Metabolic Syndrome (\%) & 32.4 & 41.9 & 0.39 \\
\hline \multicolumn{4}{|c|}{ Race $(\%)$} \\
\hline White $(n=34)$ & 56.8 & 30.2 & \\
\hline African American $(n=26)$ & 27.0 & 37.2 & \\
\hline Hispanic $(n=17)$ & 13.5 & 27.9 & 0.15 \\
\hline Asian $(n=2)$ & 2.7 & 2.3 & \\
\hline Other $(n=1)$ & 0.0 & 2.3 & \\
\hline Average Weight Change at Week $8(\mathrm{~kg})(\mathrm{SD})$ & $-2.83(2.25)$ & $-3.46(2.67)$ & 0.34 \\
\hline \multicolumn{4}{|c|}{ Baseline Diet } \\
\hline Total Calories (kcal) (SD) & $2561.1(1580.7)$ & $2003.7(1629.9)$ & 0.13 \\
\hline Protein (\% of total kcal/day) (SD) & $16.4(3.9)$ & $17.7(4.3)$ & 0.16 \\
\hline Fat (\% of total kcal/day) (SD) & $37.3(6.7)$ & $37.5(6.9)$ & 0.93 \\
\hline Carbohydrate (\% of total kcal/day) (SD) & $47.4(7.5)$ & $45.8(8.9)$ & 0.39 \\
\hline Fiber $(\mathrm{g})(\mathrm{SD})$ & $24.7(14.7)$ & $19.2(17.2)$ & 0.14 \\
\hline
\end{tabular}

HPD: High protein diet. NPD: Normal protein diet. DM: Diabetes. BMI: Body Mass Index. SD: Standard deviation. Kcal: kilocalories, g: grams.
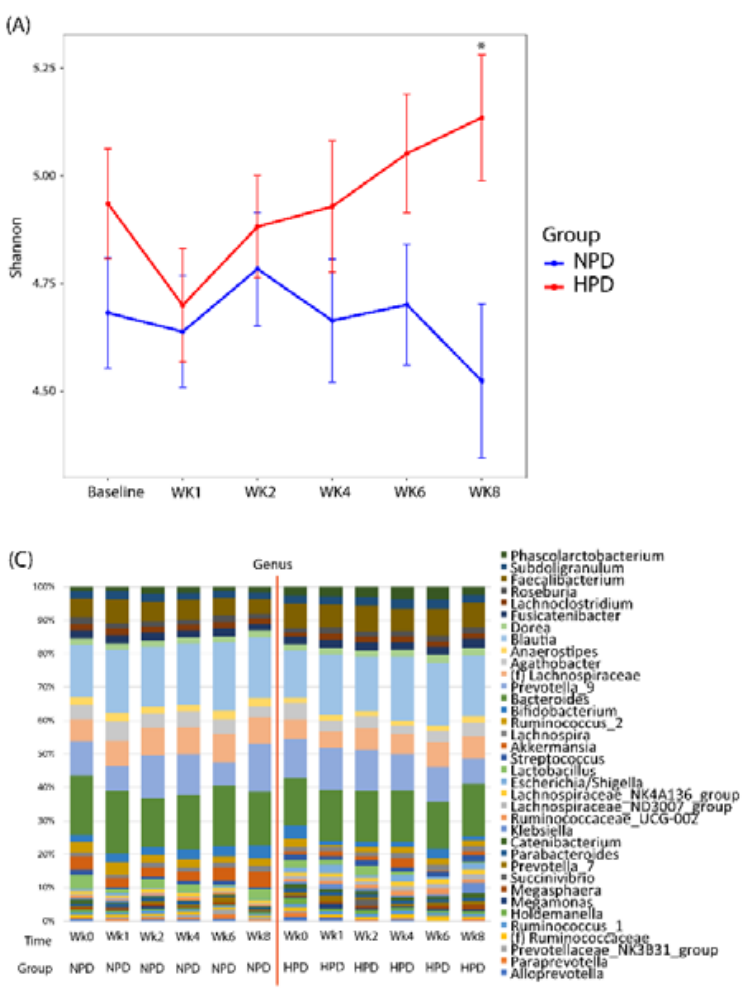
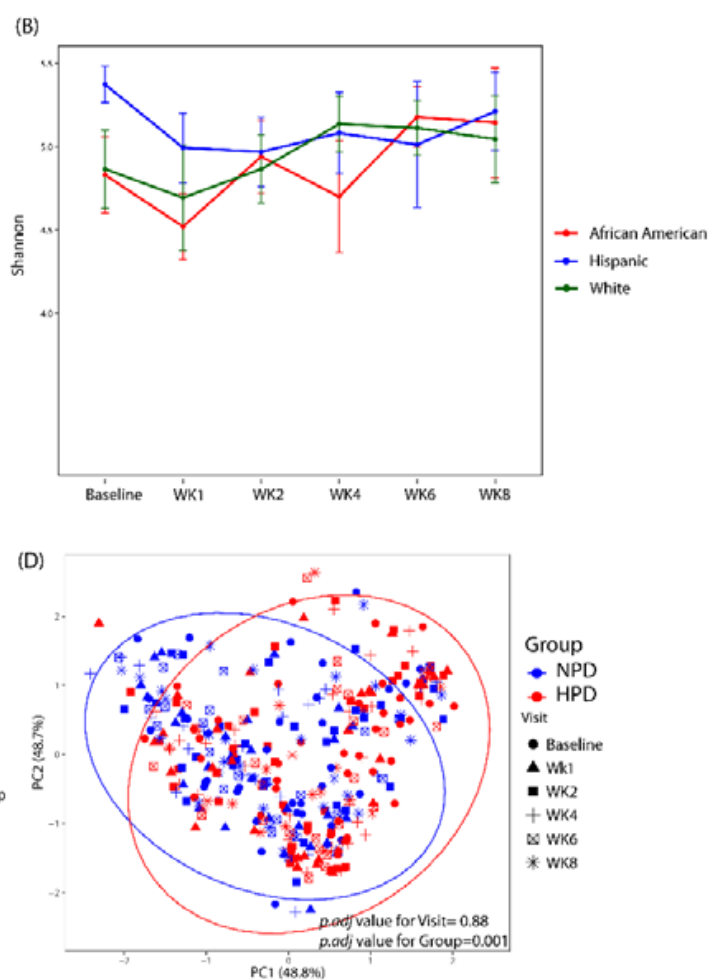

Figure 3. High protein and calorie restriction effects on microbial diversity and composition. (A) Shannon index across study visits and by intervention group. (B) Shannon index for the HPD group divided by race/ethnicity. (C) Taxonomic summary plots of genera by study visit and by group. Only genera with a relative abundance $\geq 1 \%$ are shown. (D) Principal coordinates analysis of microbial commnuity composition colored by group with shapes representing study visit. NPD: Normal protein diet. HPD: High protein diet. Wk: Week. * Denotes $p$-value $<0.05$ between the two arms. 


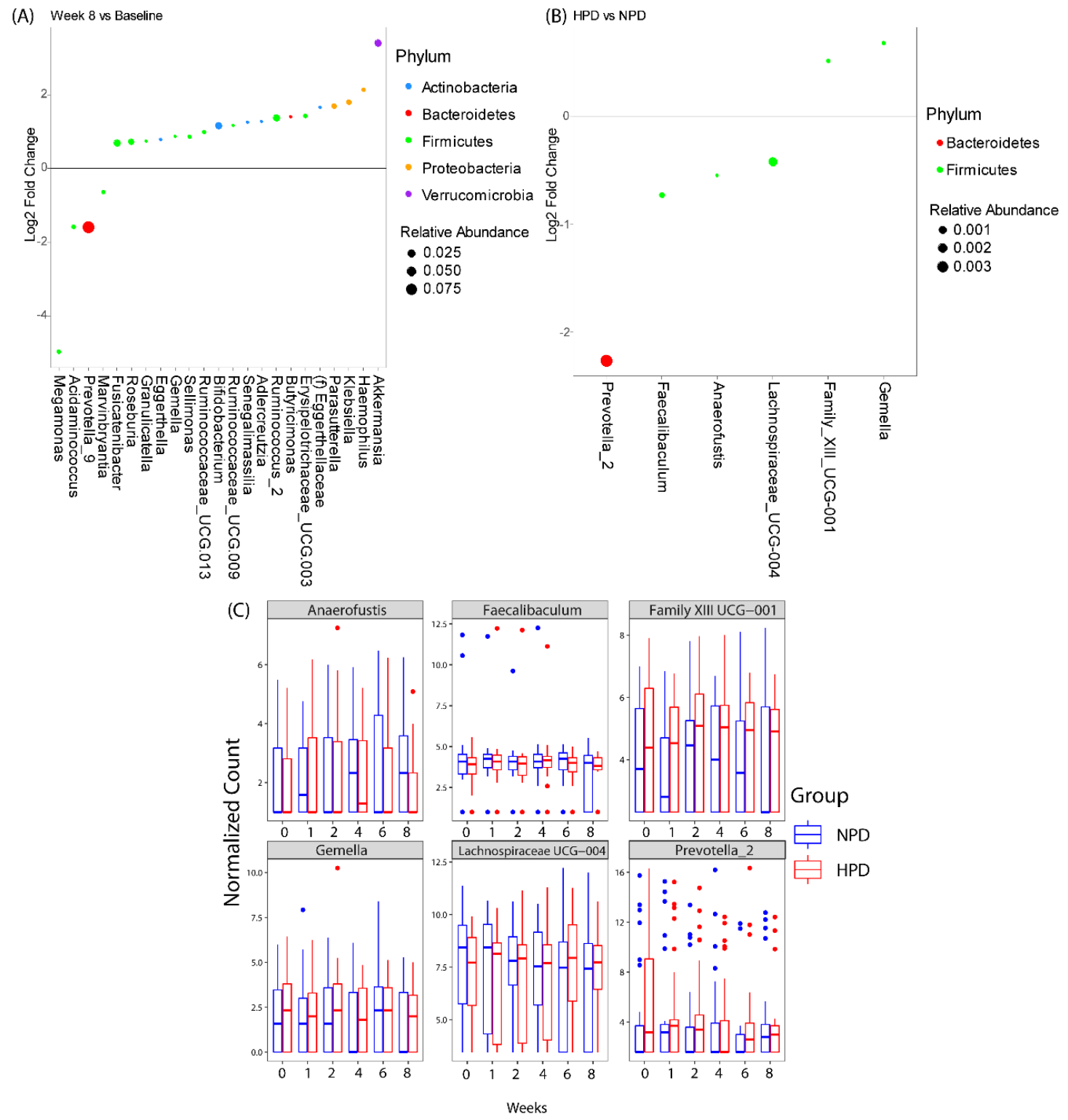

Figure 4. Differentially abundant taxa with the calorie restriction diets. Genera that were significantly different (A) at the end of week 8 as compared to baseline independent of study arm or (B) between high protein diet (HPD) and normal protein diet (NPD) group independent of study visit (incorporates data from all time points). Genera that are above 0 represent genera that have a higher abundance in patients at week 8 or on a HPD as compared to baseline or NPD, respectively. Dots are colored by phylum and sized by mean relative abundance across all samples. (C) Box plots showing DESeq2 normalized counts of the 6 genera that were differentially abundant between HPD and NPD across time points.

\section{Discussion}

We demonstrated that isocaloric calorie restriction diets significantly impact the gut microbiome of overweight and obese participants in a manner that depends on dietary protein intake. The HPD notably induced an increase in intestinal microbial diversity relative to the NPD that was primarily observed in the white and African-American subgroups. This difference between Hispanics and nonHispanic whites and African-American subgroups could be due to fact that the Hispanic subgroup started with a higher microbial diversity than the other ethnic groups. Since this group of Hispanic volunteers had higher microbial diversity, it is possible that an HPD was unable to increase it further. 
Studies have shown that Hispanics who have immigrated to the US at a later age have higher diversity than those who were either born in the US or who have immigrated when they were children [46]. While we did not ask about immigration history in our initial assessment, it is possible that a few patients in our Hispanic subgroup may have been relatively recent immigrants to the US or were living with members who have recently immigrated, thus causing them to have higher microbial diversity at baseline. Microbial diversity in the intestine is associated with health, and loss of diversity occurs with many disease states such as inflammatory bowel disease [47]. A meta- analysis of microbiome studies of obesity found a significant decrease in microbial diversity in obese individuals by measures including the Shannon index [48]. Increased diversity on an HPD may be a marker of restoration of a metabolically more favorable microbial state. Obesity is not only associated with low microbial diversity at the taxonomic level but also with low bacterial gene richness, which has been linked to inflammation and metabolic dysfunction [49]. Interestingly, an HPD was reported in a non-controlled study to increase microbial gene richness in obese subjects, suggesting that the increased compositional diversity that we observed with an HPD could also correspond to greater microbial gene richness [50].

The HPD also induced a significant shift in overall microbial composition which differed from that observed in the NPD control. At the level of individual taxa, this corresponded to a reduction in Prevotella_2 spp., a less-abundant genus within the Prevotellaceae family compared to the Prevotella_9 genus which is dominant within the gut microbiota of Western populations [51]. Prevotella_2 spp. has previously been reported to be associated with cardiovascular disease risk, suggesting that it has adverse metabolic effects and that its depletion by an HPD could have beneficial effects [52]. The HPD also enriched for Gemella spp., a group of Gram positive cocci that is a significant constituent of the microbiome of the upper gastrointestinal tract but is present at much lower levels in the colon [53]. Its enrichment in the fecal microbiota of subjects receiving an HPD suggests that this dietary change is able to modify the typical colonization range of Gemella spp. to allow extension into distal regions of the digestive tract. It is unclear if there is any functional consequence of this taxonomic shift as there is no literature on the role of intestinal Gemella spp. in obesity. Little is known about the human members of the remaining four genera that were differentially abundant on an HPD.

The mechanism by which an HPD alters the microbiome and increases richness may involve increased delivery of dietary amino acids to the distal gastrointestinal tract for bacterial fermentation. While intestinal microbes under most conditions largely derive nitrogen from endogenous sources (e.g., host glycoproteins), high dietary intake can shift the balance such that dietary protein becomes the dominant nitrogen source, thereby favoring some bacteria over others [54]. In support of this model of increased bacterial utilization of dietary protein on an HPD, a study of overweight and obese subjects on an HPD observed increased fecal levels of metabolites such as branched chain fatty acids, p-cresol, and 4-hydroxyphenylpyruvic that are consistent with amino acid fermentation [55].

It is unknown whether the effects of an HPD on the microbiome of obesity are primarily dependent on the proportion of caloric intake comprised of protein or the source of dietary protein. In our study, we prescribed a combination of protein from lean meats and plant sources, including a protein supplement derived from peas, to provide a diversity of protein sources. It has previously been reported that an animal-based vs. plant-based diet can differ greatly in their effects on the microbiome, but this may have arisen due to differences in nutritional content such as fiber rather than the source of dietary protein [25]. Existing data from preclinical protein supplementation studies suggest that distinct types of protein can have differing effects on the gut microbiome [56]. For instance, hamsters supplemented with soy protein had greater microbial diversity and altered composition including increased Bifidobacteria spp. compared to hamsters supplemented with milk protein [57].

While the microbiome effects of the HPD significantly differed from that of an NPD, both diets had a shared signature of taxonomic shifts with particularly striking induction of Akkermansia spp. This is unlikely to be an effect of calorie restriction itself, as studies of calorie restriction diets have not found evidence of changes in microbial diversity or composition [58,59]. We found that baseline levels of Akkermansia spp. were associated with fiber intake, suggesting that dietary changes shared between 
both diets including the emphasis on deriving dietary carbohydrate intake from high-fiber sources may have driven this change. Increased Akkermansia spp. is anticipated to have beneficial metabolic effects on adiposity and insulin resistance based on preclinical and human studies [31-33]. Both diets also increased fecal levels of Bifidobacterium spp. This genus has been reported to reduce insulin resistance and inflammation in animal models of metabolic syndrome $[60,61]$. Interestingly, individuals with a lactase genotype associated with increased Bifidobacterium spp. abundance had greater adiposity reduction on an HPD than those without this variant, suggesting that Bifidobacterium spp. is an important therapeutic target of HPDs [62]. In addition, both diets suppressed the predominant Prevotella genus, Prevotella_9. Prevotella spp. abundance has been reported to be enriched in obesity in a large cohort of Hispanics living in the United States and has also been associated with diabetes as well as progression of fatty liver disease $[46,63,64]$. Its suppression by both HPD and NPD may contribute significantly to the beneficial clinical outcomes with these weight loss interventions.

Our study has several key advantages compared to prior studies. It included a larger number of subjects, greater racial/ethnic diversity, frequent fecal sampling during longitudinal follow-up (six samples over 8 weeks), and high-depth sequencing with NovaSeq to allow for detection of rare taxa. However, it does have several limitations. The use of dietary counseling rather than meal replacement introduces additional variation into the study due to incomplete adherence and heterogeneity of patient dietary choices. The cohort was male-predominant, so the results may not be applicable to females. In addition, while the study was larger than prior ones, it did not have enough subjects to be powered to detect a difference in clinical outcomes such as weight loss. Finally, the microbiome analysis was based on $16 \mathrm{~S}$ rRNA sequencing, which provides data on microbial composition but not on microbial gene content or function.

In summary, we provide evidence that HPDs modulate intestinal microbiome composition in obesity. These findings support the hypothesis that microbial changes influence the outcomes of high protein dietary interventions. Additional studies with larger cohort size and longer duration are required to determine to what extent longitudinal changes in the microbiome are associated with clinical outcomes on an HPD. Incorporation of metagenomics and metabolomics to provide functional microbiome data may provide insight into mechanistic pathways that could undergo further study in preclinical models. Additional future directions could include a comparison of different protein sources and/or HPDs of varying protein content. Further understanding of the link between the microbiome and the beneficial effects of a high protein diet may spur development of therapies for obesity that directly target the microbiome to complement dietary modification.

Author Contributions: Conceptualization, J.P.J., T.S.D., J.R.P., and Z.L.; methodology, T.S.D., V.L., S.-L.W., and Z.L.; software, T.S.D., V.L., and J.Y.; validation, T.S.D. and J.P.J.; formal analysis, T.S.D.; investigation, T.S.D., K.L., V.L., F.S., S.-L.W., B.W.D., W.K., C.C., Y.Z., N.A.-J., J.Y., A.A., and J.P.J.; resources, J.P.J., J.R.P., and Z.L.; data curation, T.S.D., K.L., and V.L.; writing-original draft preparation, T.S.D. and J.P.J.; writing-review and editing, T.S.D. and J.P.J.; visualization, T.S.D.; supervision, J.P.J.; project administration, J.P.J.; funding acquisition, J.P.J. All authors have read and agreed to the published version of the manuscript.

Funding: This research was funded by the Department of Veterans Affairs, grant number IK2CX001717 (J.P.J.).

Acknowledgments: We acknowledge Nutrasumma, Inc., for donating the pea protein supplement used in this study.

Conflicts of Interest: The authors declare no conflict of interest.

\section{References}

1. Ogden, C.L.; Carroll, M.D.; Kit, B.K.; Flegal, K.M. Prevalence of childhood and adult obesity in the United States, 2011-2012. JAMA 2014, 311, 806-814. [CrossRef] [PubMed]

2. Dietz, W.H.; Baur, L.A.; Hall, K.; Puhl, R.M.; Taveras, E.M.; Uauy, R.; Kopelman, P. Management of obesity: Improvement of health-care training and systems for prevention and care. Lancet 2015, 385, 2521-2533. [CrossRef] 
3. Skov, A.R.; Toubro, S.; Ronn, B.; Holm, L.; Astrup, A. Randomized trial on protein vs carbohydrate in ad libitum fat reduced diet for the treatment of obesity. Int. J. Obes. Relat. Metab. Disord. 1999, 23, 528-536. [CrossRef] [PubMed]

4. Sacks, F.M.; Bray, G.A.; Carey, V.J.; Smith, S.R.; Ryan, D.H.; Anton, S.D.; McManus, K.; Champagne, C.M.; Bishop, L.M.; Laranjo, N.; et al. Comparison of weight-loss diets with different compositions of fat, protein, and carbohydrates. N. Engl. J. Med. 2009, 360, 859-873. [CrossRef]

5. Larsen, T.M.; Dalskov, S.M.; van Baak, M.; Jebb, S.A.; Papadaki, A.; Pfeiffer, A.F.; Martinez, J.A.; Handjieva-Darlenska, T.; Kunesova, M.; Pihlsgard, M.; et al. Diets with high or low protein content and glycemic index for weight-loss maintenance. N. Engl. J. Med. 2010, 363, 2102-2113. [CrossRef]

6. Wycherley, T.P.; Moran, L.J.; Clifton, P.M.; Noakes, M.; Brinkworth, G.D. Effects of energy-restricted high-protein, low-fat compared with standard-protein, low-fat diets: A meta-analysis of randomized controlled trials. Am. J. Clin. Nutr. 2012, 96, 1281-1298. [CrossRef]

7. Weigle, D.S.; Breen, P.A.; Matthys, C.C.; Callahan, H.S.; Meeuws, K.E.; Burden, V.R.; Purnell, J.Q. A high-protein diet induces sustained reductions in appetite, ad libitum caloric intake, and body weight despite compensatory changes in diurnal plasma leptin and ghrelin concentrations. Am. J. Clin. Nutr. 2005, 82, 41-48. [CrossRef]

8. Belza, A.; Ritz, C.; Sorensen, M.Q.; Holst, J.J.; Rehfeld, J.F.; Astrup, A. Contribution of gastroenteropancreatic appetite hormones to protein-induced satiety. Am. J. Clin. Nutr. 2013, 97, 980-989. [CrossRef]

9. Journel, M.; Chaumontet, C.; Darcel, N.; Fromentin, G.; Tome, D. Brain responses to high-protein diets. Adv. Nutr. 2012, 3, 322-329. [CrossRef]

10. Martens, E.A.; Lemmens, S.G.; Westerterp-Plantenga, M.S. Protein leverage affects energy intake of high-protein diets in humans. Am. J. Clin. Nutr. 2013, 97, 86-93. [CrossRef]

11. Johnston, C.S.; Day, C.S.; Swan, P.D. Postprandial thermogenesis is increased $100 \%$ on a high-protein, low-fat diet versus a high-carbohydrate, low-fat diet in healthy, young women. J. Am. Coll. Nutr. 2002, 21, 55-61. [CrossRef] [PubMed]

12. Tentolouris, N.; Pavlatos, S.; Kokkinos, A.; Perrea, D.; Pagoni, S.; Katsilambros, N. Diet-induced thermogenesis and substrate oxidation are not different between lean and obese women after two different isocaloric meals, one rich in protein and one rich in fat. Metabolism 2008, 57, 313-320. [CrossRef]

13. Ebbeling, C.B.; Swain, J.F.; Feldman, H.A.; Wong, W.W.; Hachey, D.L.; Garcia-Lago, E.; Ludwig, D.S. Effects of dietary composition on energy expenditure during weight-loss maintenance. JAMA 2012, 307, 2627-2634. [CrossRef]

14. Backhed, F.; Ding, H.; Wang, T.; Hooper, L.V.; Koh, G.Y.; Nagy, A.; Semenkovich, C.F.; Gordon, J.I. The gut microbiota as an environmental factor that regulates fat storage. Proc. Natl. Acad. Sci. USA 2004, 101, 15718-15723. [CrossRef] [PubMed]

15. Backhed, F.; Manchester, J.K.; Semenkovich, C.F.; Gordon, J.I. Mechanisms underlying the resistance to diet-induced obesity in germ-free mice. Proc. Natl. Acad. Sci. USA 2007, 104, 979-984. [CrossRef] [PubMed]

16. Ley, R.E.; Backhed, F.; Turnbaugh, P.; Lozupone, C.A.; Knight, R.D.; Gordon, J.I. Obesity alters gut microbial ecology. Proc. Natl. Acad. Sci. USA 2005, 102, 11070-11075. [CrossRef]

17. Turnbaugh, P.J.; Ley, R.E.; Mahowald, M.A.; Magrini, V.; Mardis, E.R.; Gordon, J.I. An obesity-associated gut microbiome with increased capacity for energy harvest. Nature 2006, 444, 1027-1031. [CrossRef]

18. Turnbaugh, P.J.; Backhed, F.; Fulton, L.; Gordon, J.I. Diet-induced obesity is linked to marked but reversible alterations in the mouse distal gut microbiome. Cell Host Microbe 2008, 3, 213-223. [CrossRef]

19. Ridaura, V.K.; Faith, J.J.; Rey, F.E.; Cheng, J.; Duncan, A.E.; Kau, A.L.; Griffin, N.W.; Lombard, V.; Henrissat, B.; Bain, J.R.; et al. Gut Microbiota from Twins Discordant for Obesity Modulate Metabolism in Mice. Science 2013, 341, 1241214. [CrossRef]

20. Vijay-Kumar, M.; Aitken, J.D.; Carvalho, F.A.; Cullender, T.C.; Mwangi, S.; Srinivasan, S.; Sitaraman, S.V.; Knight, R.; Ley, R.E.; Gewirtz, A.T. Metabolic syndrome and altered gut microbiota in mice lacking Toll-like receptor 5. Science 2010, 328, 228-231. [CrossRef]

21. Henao-Mejia, J.; Elinav, E.; Jin, C.; Hao, L.; Mehal, W.Z.; Strowig, T.; Thaiss, C.A.; Kau, A.L.; Eisenbarth, S.C.; Jurczak, M.J.; et al. Inflammasome-mediated dysbiosis regulates progression of NAFLD and obesity. Nature 2012, 482, 179-185. [CrossRef] [PubMed] 
22. Thaiss, C.A.; Itav, S.; Rothschild, D.; Meijer, M.; Levy, M.; Moresi, C.; Dohnalova, L.; Braverman, S.; Rozin, S.; Malitsky, S.; et al. Persistent microbiome alterations modulate the rate of post-dieting weight regain. Nature 2016. [CrossRef] [PubMed]

23. Albenberg, L.G.; Wu, G.D. Diet and the intestinal microbiome: Associations, functions, and implications for health and disease. Gastroenterology 2014, 146, 1564-1572. [CrossRef] [PubMed]

24. Wu, G.D.; Chen, J.; Hoffmann, C.; Bittinger, K.; Chen, Y.Y.; Keilbaugh, S.A.; Bewtra, M.; Knights, D.; Walters, W.A.; Knight, R.; et al. Linking long-term dietary patterns with gut microbial enterotypes. Science 2011, 334, 105-108. [CrossRef] [PubMed]

25. David, L.A.; Maurice, C.F.; Carmody, R.N.; Gootenberg, D.B.; Button, J.E.; Wolfe, B.E.; Ling, A.V.; Devlin, A.S.; Varma, Y.; Fischbach, M.A.; et al. Diet rapidly and reproducibly alters the human gut microbiome. Nature 2014, 505, 559-563. [CrossRef] [PubMed]

26. McAllan, L.; Skuse, P.; Cotter, P.D.; O'Connor, P.; Cryan, J.F.; Ross, R.P.; Fitzgerald, G.; Roche, H.M.; Nilaweera, K.N. Protein quality and the protein to carbohydrate ratio within a high fat diet influences energy balance and the gut microbiota in C57BL/6J mice. PLoS ONE 2014, 9, e88904. [CrossRef] [PubMed]

27. Liu, X.; Blouin, J.M.; Santacruz, A.; Lan, A.; Andriamihaja, M.; Wilkanowicz, S.; Benetti, P.H.; Tome, D.; Sanz, Y.; Blachier, F.; et al. High-protein diet modifies colonic microbiota and luminal environment but not colonocyte metabolism in the rat model: The increased luminal bulk connection. Am. J. Physiol. Gastrointest. Liver Physiol. 2014, 307, G459-G470. [CrossRef]

28. Mu, C.; Yang, Y.; Luo, Z.; Guan, L.; Zhu, W. The Colonic Microbiome and Epithelial Transcriptome Are Altered in Rats Fed a High-Protein Diet Compared with a Normal-Protein Diet. J. Nutr. 2016, 146, 474-483. [CrossRef]

29. Kiilerich, P.; Myrmel, L.S.; Fjaere, E.; Hao, Q.; Hugenholtz, F.; Sonne, S.B.; Derrien, M.; Pedersen, L.M.; Petersen, R.K.; Mortensen, A.; et al. Effect of a long-term high-protein diet on survival, obesity development, and gut microbiota in mice. Am. J. Physiol. Endocrinol. Metab. 2016, 310, E886-E899. [CrossRef]

30. Wang, L.; Jacobs, J.P.; Lagishetty, V.; Yuan, P.Q.; Wu, S.V.; Million, M.; Reeve, J.R., Jr.; Pisegna, J.R.; Tache, Y. High-protein diet improves sensitivity to cholecystokinin and shifts the cecal microbiome without altering brain inflammation in diet-induced obesity in rats. Am. J. Physiol. Regul. Integr. Comp. Physiol. 2017, 313, R473-R486. [CrossRef]

31. Zhang, H.; DiBaise, J.K.; Zuccolo, A.; Kudrna, D.; Braidotti, M.; Yu, Y.; Parameswaran, P.; Crowell, M.D.; Wing, R.; Rittmann, B.E.; et al. Human gut microbiota in obesity and after gastric bypass. Proc. Natl. Acad. Sci. USA 2009, 106, 2365-2370. [CrossRef]

32. Liou, A.P.; Paziuk, M.; Luevano, J.M., Jr.; Machineni, S.; Turnbaugh, P.J.; Kaplan, L.M. Conserved shifts in the gut microbiota due to gastric bypass reduce host weight and adiposity. Sci. Transl. Med. 2013, 5, 178 ra141. [CrossRef]

33. Everard, A.; Belzer, C.; Geurts, L.; Ouwerkerk, J.P.; Druart, C.; Bindels, L.B.; Guiot, Y.; Derrien, M.; Muccioli, G.G.; Delzenne, N.M.; et al. Cross-talk between Akkermansia muciniphila and intestinal epithelium controls diet-induced obesity. Proc. Natl. Acad. Sci. USA 2013, 110, 9066-9071. [CrossRef] [PubMed]

34. Duncan, S.H.; Belenguer, A.; Holtrop, G.; Johnstone, A.M.; Flint, H.J.; Lobley, G.E. Reduced dietary intake of carbohydrates by obese subjects results in decreased concentrations of butyrate and butyrate-producing bacteria in feces. Appl. Environ. Microbiol. 2007, 73, 1073-1078. [CrossRef]

35. Beaumont, M.; Portune, K.J.; Steuer, N.; Lan, A.; Cerrudo, V.; Audebert, M.; Dumont, F.; Mancano, G.; Khodorova, N.; Andriamihaja, M.; et al. Quantity and source of dietary protein influence metabolite production by gut microbiota and rectal mucosa gene expression: A randomized, parallel, double-blind trial in overweight humans. Am. J. Clin. Nutr. 2017, 106, 1005-1019. [CrossRef]

36. Grundy, S.M.; Cleeman, J.I.; Daniels, S.R.; Donato, K.A.; Eckel, R.H.; Franklin, B.A.; Gordon, D.J.; Krauss, R.M.; Savage, P.J.; Smith, S.C., Jr.; et al. Diagnosis and management of the metabolic syndrome: An American Heart Association/National Heart, Lung, and Blood Institute Scientific Statement. Circulation 2005, 112, 2735-2752. [CrossRef]

37. Diet Health Questionnaire III. Available online: https://epi.grants.cancer.gov/dhq3/ (accessed on 20 October 2020).

38. Subar, A.F.; Thompson, F.E.; Kipnis, V.; Midthune, D.; Hurwitz, P.; McNutt, S.; McIntosh, A.; Rosenfeld, S. Comparative validation of the Block, Willett, and National Cancer Institute food frequency questionnaires: The Eating at America's Table Study. Am. J. Epidemiol. 2001, 154, 1089-1099. [CrossRef] [PubMed] 
39. Song, S.J.; Amir, A.; Metcalf, J.L.; Amato, K.R.; Xu, Z.Z.; Humphrey, G.; Knight, R. Preservation Methods Differ in Fecal Microbiome Stability, Affecting Suitability for Field Studies. mSystems 2016, 1. [CrossRef] [PubMed]

40. Tong, M.; Jacobs, J.P.; McHardy, I.H.; Braun, J. Sampling of intestinal microbiota and targeted amplification of bacterial 16S rRNA genes for microbial ecologic analysis. Curr. Protoc. Immunol. 2014, 107, 7.41.1-7.41.11. [CrossRef]

41. Callahan, B.J.; McMurdie, P.J.; Rosen, M.J.; Han, A.W.; Johnson, A.J.A.; Holmes, S.P. DADA2: High-resolution sample inference from Illumina amplicon data. Nat. Methods 2016, 13, 581-583. [CrossRef]

42. Bolyen, E.; Rideout, J.R.; Dillon, M.R.; Bokulich, N.A.; Abnet, C.C.; Al-Ghalith, G.A.; Alexander, H.; Alm, E.J.; Arumugam, M.; Asnicar, F.; et al. Reproducible, interactive, scalable and extensible microbiome data science using QIIME 2. Nat. Biotechnol. 2019, 37, 852-857. [CrossRef] [PubMed]

43. Martino, C.; Morton, J.T.; Marotz, C.A.; Thompson, L.R.; Tripathi, A.; Knight, R.; Zengler, K. A Novel Sparse Compositional Technique Reveals Microbial Perturbations. MSystems 2019, 4. [CrossRef] [PubMed]

44. Love, M.I.; Huber, W.; Anders, S. Moderated estimation of fold change and dispersion for RNA-seq data with DESeq2. Genome Biol. 2014, 15, 550. [CrossRef] [PubMed]

45. Zhang, X.; Yi, N. Fast zero-inflated negative binomial mixed modeling approach for analyzing longitudinal metagenomics data. Bioinformatics 2020, 36, 2345-2351. [CrossRef] [PubMed]

46. Kaplan, R.C.; Wang, Z.; Usyk, M.; Sotres-Alvarez, D.; Daviglus, M.L.; Schneiderman, N.; Talavera, G.A.; Gellman, M.D.; Thyagarajan, B.; Moon, J.Y.; et al. Gut microbiome composition in the Hispanic Community Health Study/Study of Latinos is shaped by geographic relocation, environmental factors, and obesity. Genome Biol. 2019, 20, 219. [CrossRef]

47. Gilbert, J.A.; Quinn, R.A.; Debelius, J.; Xu, Z.Z.; Morton, J.; Garg, N.; Jansson, J.K.; Dorrestein, P.C.; Knight, R. Microbiome-wide association studies link dynamic microbial consortia to disease. Nature 2016, 535, 94-103. [CrossRef]

48. Sze, M.A.; Schloss, P.D. Erratum for Sze and Schloss, "Looking for a Signal in the Noise: Revisiting Obesity and the Microbiome". mBio 2017, 8. [CrossRef]

49. Le Chatelier, E.; Nielsen, T.; Qin, J.; Prifti, E.; Hildebrand, F.; Falony, G.; Almeida, M.; Arumugam, M.; Batto, J.M.; Kennedy, S.; et al. Richness of human gut microbiome correlates with metabolic markers. Nature 2013, 500, 541-546. [CrossRef]

50. Cotillard, A.; Kennedy, S.P.; Kong, L.C.; Prifti, E.; Pons, N.; Le Chatelier, E.; Almeida, M.; Quinquis, B.; Levenez, F.; Galleron, N.; et al. Dietary intervention impact on gut microbial gene richness. Nature 2013, 500, 585-588. [CrossRef]

51. Wallen, Z.D.; Appah, M.; Dean, M.N.; Sesler, C.L.; Factor, S.A.; Molho, E.; Zabetian, C.P.; Standaert, D.G.; Payami, H. Characterizing dysbiosis of gut microbiome in PD: Evidence for overabundance of opportunistic pathogens. NPJ Parkinson's Dis. 2020, 6, 11. [CrossRef]

52. Kelly, T.N.; Bazzano, L.A.; Ajami, N.J.; He, H.; Zhao, J.; Petrosino, J.F.; Correa, A.; He, J. Gut Microbiome Associates With Lifetime Cardiovascular Disease Risk Profile Among Bogalusa Heart Study Participants. Circ. Res. 2016, 119, 956-964. [CrossRef] [PubMed]

53. Vasapolli, R.; Schutte, K.; Schulz, C.; Vital, M.; Schomburg, D.; Pieper, D.H.; Vilchez-Vargas, R.; Malfertheiner, P. Analysis of Transcriptionally Active Bacteria Throughout the Gastrointestinal Tract of Healthy Individuals. Gastroenterology 2019, 157, 1081-1092.e3. [CrossRef] [PubMed]

54. Holmes, A.J.; Chew, Y.V.; Colakoglu, F.; Cliff, J.B.; Klaassens, E.; Read, M.N.; Solon-Biet, S.M.; McMahon, A.C.; Cogger, V.C.; Ruohonen, K.; et al. Diet-Microbiome Interactions in Health Are Controlled by Intestinal Nitrogen Source Constraints. Cell Metab. 2017, 25, 140-151. [CrossRef]

55. Gratz, S.W.; Hazim, S.; Richardson, A.J.; Scobbie, L.; Johnstone, A.M.; Fyfe, C.; Holtrop, G.; Lobley, G.E.; Russell, W.R. Dietary carbohydrate rather than protein intake drives colonic microbial fermentation during weight loss. Eur. J. Nutr. 2019, 58, 1147-1158. [CrossRef]

56. Prokopidis, K.; Cervo, M.M.; Gandham, A.; Scott, D. Impact of Protein Intake in Older Adults with Sarcopenia and Obesity: A Gut Microbiota Perspective. Nutrients 2020, 12, 2285. [CrossRef]

57. Butteiger, D.N.; Hibberd, A.A.; McGraw, N.J.; Napawan, N.; Hall-Porter, J.M.; Krul, E.S. Soy Protein Compared with Milk Protein in a Western Diet Increases Gut Microbial Diversity and Reduces Serum Lipids in Golden Syrian Hamsters. J. Nutr. 2016, 146, 697-705. [CrossRef] 
58. Zou, H.; Wang, D.; Ren, H.; Cai, K.; Chen, P.; Fang, C.; Shi, Z.; Zhang, P.; Wang, J.; Yang, H.; et al. Effect of Caloric Restriction on BMI, Gut Microbiota, and Blood Amino Acid Levels in Non-Obese Adults. Nutrients 2020, 12, 631. [CrossRef]

59. Ott, B.; Skurk, T.; Hastreiter, L.; Lagkouvardos, I.; Fischer, S.; Buttner, J.; Kellerer, T.; Clavel, T.; Rychlik, M.; Haller, D.; et al. Effect of caloric restriction on gut permeability, inflammation markers, and fecal microbiota in obese women. Sci. Rep. 2017, 7, 11955. [CrossRef]

60. Cani, P.D.; Neyrinck, A.M.; Fava, F.; Knauf, C.; Burcelin, R.G.; Tuohy, K.M.; Gibson, G.R.; Delzenne, N.M. Selective increases of bifidobacteria in gut microflora improve high-fat-diet-induced diabetes in mice through a mechanism associated with endotoxaemia. Diabetologia 2007, 50, 2374-2383. [CrossRef] [PubMed]

61. Amar, J.; Chabo, C.; Waget, A.; Klopp, P.; Vachoux, C.; Bermudez-Humaran, L.G.; Smirnova, N.; Berge, M.; Sulpice, T.; Lahtinen, S.; et al. Intestinal mucosal adherence and translocation of commensal bacteria at the early onset of type 2 diabetes: Molecular mechanisms and probiotic treatment. EMBO Mol. Med. 2011, 3, 559-572. [CrossRef]

62. Heianza, Y.; Sun, D.; Ma, W.; Zheng, Y.; Champagne, C.M.; Bray, G.A.; Sacks, F.M.; Qi, L. Gut-microbiomerelated LCT genotype and 2-year changes in body composition and fat distribution: The POUNDS Lost Trial. Int. J. Obes. 2018, 42, 1565-1573. [CrossRef] [PubMed]

63. Pedersen, H.K.; Gudmundsdottir, V.; Nielsen, H.B.; Hyotylainen, T.; Nielsen, T.; Jensen, B.A.; Forslund, K.; Hildebrand, F.; Prifti, E.; Falony, G.; et al. Human gut microbes impact host serum metabolome and insulin sensitivity. Nature 2016, 535, 376-381. [CrossRef]

64. Dong, T.S.; Katzka, W.; Lagishetty, V.; Luu, K.; Hauer, M.; Pisegna, J.; Jacobs, J.P. A Microbial Signature Identifies Advanced Fibrosis in Patients with Chronic Liver Disease Mainly Due to NAFLD. Sci. Rep. 2020, 10, 2771. [CrossRef] [PubMed]

Publisher's Note: MDPI stays neutral with regard to jurisdictional claims in published maps and institutional affiliations. 